\title{
Libro: La República desolada. Los cambios políticos de la Argentina (2001-2009)
}

Hugo Quiroga

Edhasa, Buenos Aires, 2010 (212 pp.)

\section{Mariana Berdondini}

Licenciada en Ciencia Política. Becaria de CONICET por la Facultad de Ciencia Política y Relaciones Internacionales de la Universidad Nacional de Rosario y Docente de la Facultad de Trabajo Social de la Universidad Nacional de Entre Ríos, Argentina.

E- mail: marianaberdondini@yahoo.com.ar

A través de la articulación teórico-política entre la tradición democrática, la republicana y la liberal, este libro muestra los desafíos de la política actual, revisando los cambios y manifestaciones recientes de la vida democrática argentina. En este sentido, describe las transformaciones políticas en los últimos años -entre 2001 y 2009- desde una perspectiva republicana de "buen gobierno" y "vida en común", considerando como dimensiones centrales de su análisis a las libertades políticas, las instituciones deliberativas, la división de poderes y la consistencia del control sobre las decisiones del Estado así como el rol de la ciudadanía.

Signada por la "política del ejecutivo" y la "política de la calle", tres interrogantes atraviesan la obra: “¿cómo se reorganizará el régimen político si persiste la desconfianza hacia la representación, en tanto distintivo de la democracia contemporánea?, ¿en qué medida los cambios políticos tensionan el molde clásico de la democracia?, y ¿hasta qué punto la informalización de la política no desinstitucionaliza la política representativa o hasta qué punto la insuficiencia de ésta no retroalimenta la política informal?" (p. 15).

De este modo, el autor resitúa y significa desde un punto de vista histórico y conceptual la las diferentes expresiones, formales e informales, los cambios institucionales, que asume la actividad política democrática del país. A lo largo de los capítulos, Quiroga hace "viajar" al lector partiendo de la convulsionada crisis política de 2001, sus efectos, las reacciones sociales y las respuestas políticas, para llegar al acto electoral de 2003. La crisis de 2001 fue la más visible dislocación de la esfera política desde 1983, alterando el régimen político entendido como la organización de los poderes, sus instituciones y procedimientos y las inflexiones de la vida en común (p. 17). Emerge un doble fenómeno de deslegitimación y desinstitucionalización de la política que se separa de los problemas cotidianos y no puede garantizar los intercambios entre gobierno y ciudadanos. El conflicto y el cuestionamiento a la acción gubernamental y ciertas prácticas partidarias hacen que la política se retire de los canales formales para instalarse en las asambleas populares y en la participación directa. La calle se constituye en el ámbito de acción política y se legitima la idea de un poder colectivo.

Así, Quiroga refleja el desorden político y económico que signó la transición entre la renuncia de De la Rúa y el gobierno de Duhalde, en el que se profundizan 
las medidas decisionistas aplicadas en la Argentina desde 1989. A partir de la respuesta gubernamental dada en 2002 vía la devaluación y pesificación con sus altos costos sociales, y los proyectos de reforma política en el contexto del "que se vayan todos", se llega a los pedidos de una Convención Constituyente y la caducidad de los mandatos. Hace en este capítulo un interesante señalamiento de las prácticas políticas durante el período 2001-2003 en el que, paradójicamente, representantes y ciudadanía en su intento de reconstruir la legitimidad política, hallan en la apelación a procedimientos inconstitucionales la salida posible. No obstante, serán las elecciones de 2003, el acto electoral, y la presencia de los ciudadanos en las urnas lo que permitirá relegitimar la política, estrechándose a partir de entonces la relación entre ciudadanía y sufragio. Se explica por la fragmentación del régimen de partidos, la dilución de las identidades políticas masivas, la personalización de la política y la volatilidad electoral que asoman luego del "cataclismo" de 2001 (p. 38) y que son desarrolladas en su justa medida en el capitulo quinto.

La legitimidad de las instituciones asimilada a la legalidad que proviene de la Constitución, junto con la legitimidad de ejercicio o de gobierno entran en tensión en esta coyuntura a la que Quiroga trasciende en su análisis, señalando los componentes teóricos, históricos y culturales. El divorcio entre política y sociedad, entre representantes y representados, gobernantes y gobernados, políticos y ciudadanos, implicaban la tarea de relegitimación de la política. Para el autor esa fue la labor que cumplió el presidente Kirchner a partir de su elección en mayo de 2003. La contracara fue la construcción de un sistema de poder vertical y concentrado, poco respetuoso de la deliberación pública y de la división de poderes. Los capítulos tercero y cuarto están dedicados a la descripción y análisis de estas dimensiones.

Quiroga conceptualiza la construcción política por parte de Néstor Kirchner desde su llegada a la Presidencia como "la arquitectura del poder decisionista". Una rica discusión teórica sobre la noción de poder posibilita al autor advertir como Kirchner logra a pocos meses de su asunción revertir a través de la legitimidad de ejercicio, la frágil legitimidad que había obtenido en las urnas (22\%). Las variables de estabilidad y crecimiento económico explican sólo en parte el avance del poder de Kirchner. En este sentido, tres soportes centrales permitieron instalar una perspectiva de poder kirchnerista de largo alcance que se consolida en 2006 (p. 106): la cooptación interesada, la erosión de las identidades colectivas, y el abuso de los poderes discrecionales del ejecutivo vinculados mutuamente (p. 54). Pero también la voluntad de poder y la cultura política están fuertemente entrelazadas (p. 69), involucrando tanto a gobernantes como a ciudadanos. Es el desarrollo de las piezas esenciales que constituyen la "arquitectura del poder decisionista", característica central de la vida política en esos años, a lo que se aboca a partir de entonces en el libro.

En el tercer capítulo, Quiroga argumenta la conexión entre decisionismo y poder fiscal. El centro del poder decisionista se explica por la "apropiación" del poder fiscal del gobierno federal, el manejo discrecional de los recursos fiscales por parte del Presidente que apelando a la "emergencia permanente" se concentran en el Ejecutivo. Como muestra el autor, este mecanismo es avalado por el marco 
normativo y le confiere al Ejecutivo la capacidad de distribuir favores, comprar voluntades, intervenir y modificar las reglas del juego económico, sin los controles debidos de los usos que pueden hacerse de ese poder. Con énfasis en el período 2003-2009 analiza el cuadro normativo de facultades delegadas señalando así el modo en que se afianza la idea del "ejecutivo como autoridad legislativa delega$d a$ ", para luego analizar la reglamentación de los decretos de necesidad y urgencia y el unitarismo fiscal que se completa con la norma que regula el Consejo de la Magistratura desarrollado en el capítulo cuarto.

Se configura para Quiroga una práctica de "decisionismo democrático" como derecho de mandar vertical y concentrado, que sustenta su acción política tanto en la ley como en las medidas de emergencia empleadas en épocas de normalidad. Al tiempo que presupone en parte una ciudadanía pasiva, no se explica sin la conexión estructural de los tres poderes del Estado cuyas atribuciones y competencias, establecidas en la Constitución, dan forma y contenido al Estado de derecho democrático: "es una combinación del gobierno de los hombres, del gobierno atenuado del Estado de derecho y de la ausencia de poder de contralor". La decisión esquiva los controles parlamentarios y judiciales y únicamente se siente obligada frente al veredicto popular (p. 98).

Se complementa, en cuarto lugar, con un análisis desde la noción de Estado de Derecho atenuado. El decisionisno democrático es decisionista y normativista a la vez, sin embargo, es una forma de ejercicio del poder no republicano, marcado por el ejercicio de los plenos poderes a través de decretos de necesidad y urgencia, la delegación legislativa y el veto parcial. Esta práctica de gobierno genera un cambio en la base del poder de la democracia republicana que tiene implicancias sobre el análisis del presidencialismo y la división de poderes del Estado, revisando los conflictos específicos con relación al Congreso y al Poder Judicial como contraparte de la concentración del poder en el Ejecutivo. Pero también la libertad de prensa y la conflictiva relación con los medios de comunicación son tratadas por Quiroga en este apartado.

La "sociedad mediática" ha provocado cambios en las condiciones de la acción política y en el funcionamiento de las estructuras partidarias. En el quinto capítulo, Quiroga aborda la disgregación de los partidos a la luz del estado del sistema de partidos, signado por la fragmentación de los viejos partidos tradicionales -el peronismo y el radicalismo-, la fluctuación del voto, la territorialidad de la política, la migración de dirigentes y la dilución de las identidades políticas. Éstas condicionan las características políticas actuales y con ello la política de las coaliciones, los resultados electorales del período y los efectos sobre el régimen político considerando las orientaciones de la ciudadanía junto con una resignificación de la figura presidencial (p. 159) dada por un liderazgo bicéfalo y la figura opositora del vicepresidente. El régimen de representación se halla plenamente afectado por el vaciamiento institucional de los partidos, que, al perder su función de intermediación, dejan a los ciudadanos en relación directa con los liderazgos personales (p. 162). Finaliza el capítulo con la reforma política que condensa estos cambios en el sistema de partidos nacional y el estado de la representación sindical. 
El sexto y último capítulo se aboca a la vida democrática integrando las dimensiones de análisis antes trabajadas, en el que incorpora tanto los aspectos políticos como sociales. Lo diferencial del argumento que Quiroga trabaja reside en lo que conceptualiza como "el costado informal de la democracia", contracara de la democracia representativa: ante la crisis de los dispositivos tradicionales, los partidos y el parlamento, y la superioridad del ejecutivo, intervienen actores informales que buscan limitar los abusos del poder a través de la acción informal de ciudadanos y grupos (p. 173). La calle se constituye en un ámbito de interpelación a la sociedad y de presión al Estado. Se trata de "contrapesos sociales" (contrapoderes) que configuran la democracia informal como contrapeso de la democracia representativa (p. 176). La expresión de esta dimensión de la democracia es revisada por el autor a partir de los conflictos entre derechos e intereses vinculados a políticas públicas que presentaron tensiones y desafíos en la construcción de poder kirchnerista. Es el caso de la protesta social en Gualeguaychú que desencadenó el conflicto con Uruguay y el conflicto con el campo. Este segmento del libro concluye con la pregunta acerca del fin del kirchnerismo y el contexto que se inaugura a inicios de 2010 con miras a la elección presidencial de 2011.

$\mathrm{Al}$ análisis de cada uno de estos aspectos dedica el autor los respectivos capítulos, profundizándolos a través de un extenso bagaje teórico político y citas bibliográficas que se complementan con hechos y acontecimientos del período 20012009. Documentados a partir de normativa, entrevistas periodísticas, columnas, notas de opinión, declaraciones publicadas por diarios nacionales o regionales, resultados electorales, logra enriquecer el análisis de los sucesos y cambios de la política democrática del país.

El libro "La República desolada" de Hugo Quiroga constituye un capítulo imprescindible para reflexionar sobre las condiciones y transformaciones actuales de la política argentina, caracterizando las tensiones y los desafíos entre los principios democráticos y republicanos implicados e inaugurando nuevos interrogantes que apelan a lo profundo de la historia y cultura política pero, fundamentalmente, al sentido de los días que corren. 